\title{
Os dois Oskar Matzerath
}

\author{
Elisandra de Souza Pedro '
}

\begin{abstract}
Resumo: O presente trabalho analisa a estrutura narrativa do romance O tambor (Die Blechtrommel) de Günter Grass e do filme homônimo dirigido por Volker Schlöndorff, observando a forma como o romancista articula a construção complexa de seu foco narrativo e como o cineasta trabalha essa estrutura em seu filme, o que resulta em diferentes formas de perceber e interpretar tanto o narradorpersonagem quanto o universo no qual está inserido, levando em consideração que a discussão sobre adaptações de obras literárias em realizações cinematográficas já passou da discussão moralizante da fidelidade ou traição para uma discussão menos valorativa. $O$ artigo enfatiza o estudo da intertextualidade entre a adaptação cinematográfica e o romance original, tendo como pontos de observação o tipo de seleção feita no processo da realização fílmica, a concretização visual do texto literário, a atualização de determinados temas abordados na obra e o foco narrativo, por exemplo.
\end{abstract}

Palavras-Chave: literatura alemã; cinema; estrutura narrativa; Günter Grass.

\begin{abstract}
The purpose of this work is to analyze the narrative structure of the novel by Günter Grass DieBlechtrommel, and the film with the same title, by Volker Schlöndorff, observing, on the one hand, the way the writer articulates the construction of his narrative point of view and, on the other hand, how the movie maker builds the structure of his film, which then results in different ways of perception and interpretation on the part of the character-narrator and the universe of which he is part. The article emphasizes the intertextual relationship between the film adaptation and the original novel, focusing on the selection of elements for the filmic process and for turning the visual aspects of the literary text concrete.
\end{abstract}

Key-words: German literature, film, narrative structure, Günter Grass

Zusammenfassung: Diese Arbeit beabsichtigt, die narrative Struktur des Romans Die Blechtrommel von Günter Grass und die des gleichnamigen Filmes von Volker Schlöndorff zu analysieren, um dabei zu beobachten, wie der Autor die komplexe Erzählsituation artikuliert und wie der Regisseur diese

\footnotetext{
${ }^{1}$ Mestre em Letras, Língua e Literatura Alemã pela Faculdade de Filosofia, Letras e Ciências Humanas da Universidade de São Paulo (FFLCH - USP). Email: elisandrasp@ yahoo.com.br . Esse artigo procura expor em linhas gerais os argumentos desenvolvidos em minha dissertação de mestrado. Cf. PEDRO, Elisandra de Souza. Estratégias Narrativas em O tambor: o diálogo entre a literatura e o cinema. São Paulo: USP - FFLCH. Dissertação de Mestrado, 2009.
} 


\section{Pedro, E. S. - Os dois Oskar Matzerath}

Struktur in seinem Film bearbeitet, was zu unterschiedlichen Wahrnehmungen und Interpretationen der Erzählfigur und ihres Universums führt. Es wird berücksichtigt, dass die Diskussion um die filmische Umsetzung literarischer Werke inzwischen das moralistische Gebiet der "Treue" oder des "Verrates" verlassen hat und zu einer weniger wertenden Diskussion übergegangen ist. Dies führte zu einer Fokussierung auf die Intertextualität zwischen dem adaptierten Film und dem ursprünglichen Roman, die als Beobachtungspunkte z.B. die Auswahl untersucht, die während des Prozesses der filmischen Herstellung gemacht wurde, wie auch die visuelle Verkörperung des literatischen Textes und die Aktualisierung mancher im Werk angesprochenen Themen und der Erzählsituation .

Stichwörter: Deutsche Literatur; Film; Narrative Struktur; Günter Grass.

\section{1 - Apresentação}

Oskar Matzerath desperta em seus leitores e críticos reações e interpretações que se encontram em descrições presentes na literatura a respeito da obra e que deixam evidente o quanto essa personagem incomodou e continua incomodando o universo literário: "trommelschlagenden Kretin" (cretino tocador de tambor), "quäkenden Gnom mit dem Froschleib" (um gnomo que coaxa e tem corpo de sapo), "gräßlichen Brüller" (gritador horrível), "fantastischen Säugling und Wechselbalg” (fantástico bebê traquinas), “Oskar oder das Monstrum" (Oskar ou o monstro), "ein Zwerg, ein Krüppel, ein Paranoiker, eine phantastische Ausgeburt des Zwanzigsten Jahrhunderts" (um anão, um deformado, um paranóico, um fantástico produto infernal do século XX). Oskar Matzerath não se limitou ao universo literário de Günter Grass e também se tornou conhecido pela adaptação do romance por Volker Schlöndorff.

Em entrevista a Günter BARUDIO para a revista Filmfaust de 1979, na ocasião do lançamento do filme $O$ tambor (Die Blechtrommel), Günter GRASS, ao ser questionado sobre como ele entendia as modificações apresentadas na adaptação cinematográfica de seu romance e como ele interpretava tais modificações, cortes ou adaptações, respondeu ao jornalista que "em um filme, o literário é sacrificado".2

Contudo, ao pensar na relação interativa do espectador com a literatura e o cinema, tornou-se lugar-comum formular juízos de valor a respeito de um filme que tem como base uma obra literária, exaltando, na maioria das vezes, o livro, como se o cinema prestasse 


\section{Pedro, E. S. - Os dois Oskar Matzerath}

serviço à literatura. Esse tipo de lugar-comum vai ao encontro do que Grass formula, pois o espectador, muitas vezes, acaba escolhendo como principal critério de avaliação a fidelidade em relação, no caso, ao romance adaptado.

A avaliação que o espectador apresenta quando refere-se à fidelidade ou a sua ausência em determinada adaptação deve ser levada em consideração, mas não pode ser encarada como único elemento de análise. Tornando a questão mais complexa, um questionamento possível seria: será possível a fidelidade no caso das adaptações de obras literárias para o cinema? Esse é um dos questionamentos que sempre esteve presente na discussão sobre a relação entre os dois universos, o cinematográfico e o literário. Pode-se pensar que, da mesma forma que qualquer texto literário pode gerar uma infinidade de leituras, qualquer romance pode gerar uma série de adaptações. Em sua declaração, Grass parece se referir à utilização de processos e meios distintos em cada universo, os quais se valem de ferramentas distintas para contar suas histórias.

Aspectos de aproximação, distanciamento e choque entre os dois meios tornam possível a análise da estrutura narrativa do romance de Günter GRASS Die Blechtrommel ( $O$ tambor, 1959) e da adaptação cinematográfica de Volker SCHLÖNDORFF Die Blechtrommel (O tambor, 1978) a partir dos inícios narrativos de cada obra, determinantes para o desdobramento de cada narrativa e da caracterização da personagem central e narrador, Oskar Matzerath. O recorte aqui apresentado se refere apenas aos dois primeiros livros do romance.

A escolha por esses objetos se deu não somente pela importância do romance no contexto da literatura alemã e mundial e pelo reconhecimento internacional do filme, mas também pela complexidade e interesse que a personagem central, Oskar Matzerath, desperta e pelas estratégias de seu criador utiliza para contar sua trajetória.

O tambor é o primeiro romance de Günter Grass, publicado em 1959. O romance lhe rendeu críticas ferozes a respeito do conteúdo e da intenção de Grass ao abordar sua matéria histórica, a primeira metade do século XX, período de transição da República de Weimar para o nacional-socialismo e o pós-guerra. Este recorte dá corpo à estrutura de ambas as narrativas, contadas por um indivíduo, segundo a crítica da época, deformado em vários sentidos, Oskar Matzerath. Esse narrador tem o plano de, por meio do "registro exato de suas memórias",

\footnotetext{
2 “Im Filmbild bleibt das Literarische auf der Strecke”. (BARUDIO 1979: 19)
} 


\section{Pedro, E. S. - Os dois Oskar Matzerath}

articular esse período e apresentar outros acontecimentos pregressos à sua existência, desde 1889 até 1924.

Embora o palco de sua narrativa seja Danzig (atual Gdansk, na Polônia), cidade natal do escritor e também ambiente da Trilogia de Danzig - da qual fazem parte outras duas obras, Gato e rato (Katz und Maus, 1961) e Anos de cão (Hundejahre, 1963) -, os fatos narrados não dizem respeito exclusivamente a essa cidade e a seu histórico particular de diversas transformações políticas. Antes, Grass a transforma em um microcosmo, refletindo os eventos transcorridos na Europa daquela época.

\section{2 - $\bigcirc$ romance}

Na literatura a respeito de Die Blechtrommel, percebe-se que é dedicada grande atenção, ou atenção especial, ao primeiro período do romance:

Zugegeben: Ich bin Insasse einer Heil-und Pflegeanstalt. Mein Pfleger beobachtet mich, läßt mich kaum aus dem Auge, denn in der Tür ist ein Guckloch, und meines Pflegers Auge ist von jenem Braun, welches mich, den Blauäugigen, nicht durchschauen kann (p. 9). ${ }^{3}$

Admito: sou interno de um hospício. Meu enfermeiro está me observando, quase nunca tira os olhos de mim; porque na porta há um postigo e os olhos do meu enfermeiro são desse castanho que não consegue penetrar o azul dos meus (p.11).

Ele funciona como catalisador da atenção do leitor para o universo que ali será apresentado, como ponto de partida para a análise e interpretação da personagem narradora e da estrutura narrativa construída a partir dela.

O primeiro contato do leitor com o texto se dá por meio desse momento de confissão, cujo produtor não é possível inicialmente identificar. Tem-se apenas noção da condição de interno de um hospício, condição que por si projeta muitos questionamentos e suposições a respeito da personagem e da narração que está sendo iniciada. A partir dessa confissão, o

\footnotetext{
${ }^{3}$ Este artigo recorrerá à edição alemã Die Blechtrommel. Frankfurt a. M: Fischer Bücherei, 1960 e à edição brasileira do romance $O$ tambor. Tradução de Lúcio Alves. Rio de Janeiro: Nova Fronteira, 1982. Todas as citações se referem a essas edições, apresentando ao final a indicação do número da página na qual consta a citação.
} 


\section{Pedro, E. S. - Os dois Oskar Matzerath}

narrador vai configurando seu universo, mantendo diálogo com seu suposto leitor, que não sabe quem ele é, nem por que ou há quanto tempo ele está naquele local.

A necessidade de alguns esclarecimentos a respeito do narrador, e sua narrativa, fará com que se inicie um percurso em busca de respostas, as quais serão oferecidas ao longo de seu relato, construído de forma peculiar, estruturado como um projeto da escritura de suas memórias.

A afirmação da necessidade de isolamento - condição dada pela permanência no hospício, repetida e intensificada ao longo da narrativa - torna a instituição, segundo a perspectiva do narrador, um ambiente seguro para que ele possa contar sua história. Isso produz uma inversão de papéis e valores. É importante, segundo a perspectiva do narrador, que se perceba que a segurança, a sanidade e a realidade estariam no ambiente do hospício e não do lado de fora, no contato com o que seria, para os que o cercam, o mundo real, como se a cama de hospício fosse uma cela segura, principalmente para a realização de seus propósitos. O narrador deixa claro, antes mesmo de sua apresentação "formal”, qual o objetivo de sua empreitada, o "registro exato de suas memórias", como é afirmado na seguinte passagem:

Bruno, $[\ldots]$ me trará mais um pouco do espaço em branco para o que espero que seja o registro exato de minhas memórias. Nunca poderia ter pedido esse favor aos meus visitantes, ao advogado, por exemplo, ou a Klepp. A solícita afeição prescrita para o meu caso teria certamente impedido os meus amigos de me trazer algo tão perigoso como papel em branco e pô-lo à disposição das sílabas que meu espírito segrega (p. $13)^{4}$

No entanto, como esperar de um paciente de uma clínica psiquiátrica que o registro exato de suas memórias seja realmente o que ele oferece? Oskar quer convencer o leitor de que os fatos a serem narrados respeitam a verdade. Antes, contudo, o narrador procurará organizar suas lembranças de modo a tornar plausível ao leitor que seu relato é o registro exato, a objetivação de sua experiência subjetiva.

\footnotetext{
4 „Bruno, [...] noch einmal aufsuchen und mir den notwendigen unlinierten Platz für mein hoffentlich genaues Erinnerungsvermögen beschaffen. Niemals hätte ich meine Besucher, etwa den Anwalt oder Klepp, um diesen Dienst bitten können. Besorgte, mir verordnete Liebe hätte den Freunden sicher verboten, etwas so Gefährliches wie unbeschriebenes Papier mitzubringen und meinem unablässig Silben ausscheidenden Geist zum Gebrauch freizugeben.” (p.10)
} 


\section{Pedro, E. S. - Os dois Oskar Matzerath}

Renate GERSTENBERG, em seu estudo sobre as técnicas de narração ou estratégias narrativas de Günter Grass, Zur Erzähltechnik von Günter Grass (1980), detém-se na análise do início do romance. Em sua percepção, "a primeira frase apresenta in nuce todos os elementos que determinam a perspectiva narrativa". 5 autora analisa a construção da frase, as palavras utilizadas e de que forma essa construção se refletirá no desdobramento da narrativa, justificando, inclusive, as atitudes de Oskar ao longo do romance, sua relação com o enfermeiro Bruno, sua percepção como herói do romance e a estratégia narrativa utilizada por Oskar ao narrar-se em terceira pessoa - movimento que a autora considera irônico, com a personagem tratando a si mesma como um "Erzählobjekt".

Paul F. BOTHEROYD, em seu estudo Ich und er (1976), apresenta a interpretação de que, a partir da primeira incursão do narrador no romance, o leitor é colocado diante de uma postura irônica e distanciada, o que o prepara para o que será narrado, e convida-o a aceitar essa atitude que, de outro modo, consideraria fora dos padrões narrativos. O mundo do leitor seria confrontado com o mundo apresentado por Oskar, a clínica e suas obsessões, o que determina a tensão narrativa aos olhos do primeiro, testado o tempo todo pelos dois universos, o do hospício e o das memórias, além de ter os chamados valores sociais desafiados pelos valores morais de Oskar.

Até aqui, tratou-se do narrador a partir de uma confissão. Percebe-se que, apenas depois de configurar minimamente o universo que o cerca e seus interlocutores - o enfermeiro, no âmbito interno, e o leitor desafiado, no externo -, ele é finalmente nomeado na narrativa, em um discurso direto de seu enfermeiro, reproduzido por ele mesmo.

Quando eu disse para Bruno: “Oh, Bruno, você compraria quinhentas folhas de papel virgem?", ele, olhando o teto e com o dedo indicador apontado na mesma direção em busca de um termo de referência, replicou: "De papel branco, Senhor Oskar?" (p. 13)

Após sua nomeação, ainda que de forma indireta, o narrador descreve o processo de escritura das memórias, tratado de forma minuciosa - desde os suprimentos materiais (papel, tinta,

\footnotetext{
5 “Dieser erste Satz der Blechtrommel erhält in nuce alle Elemente, die die Erzählperspektive bestimmen". (GERSTENBERG 1980: 21)
} 


\section{Pedro, E. S. - Os dois Oskar Matzerath}

álbum de fotografias que servirá como elemento crucial para o plano) e de reflexões a respeito da crise do romance moderno - no que se refere a aspectos formais, como o problema de configuração de espaço e tempo, que serão questões bastante trabalhadas ao longo do romance, construindo uma estrutura espaço-temporal complexa na montagem do universo ficcional. Também apresenta um questionamento a respeito da figura do herói romanesco. Sobre esse último aspecto, denomina a si e a seu enfermeiro como heróis, pelo menos no que diz respeito ao plano narrativo. Mas a continuidade da narrativa mostra que essa classificação não é sustentável. Após a leitura do romance, essa afirmação parece irônica, pois o herói Oskar Matzerath estaria longe do que se espera de um herói, como é descrito por Georg Lukács na Teoria do romance (1965). O herói romanesco que é movido pela busca, por meio da qual se desenvolve, é um indivíduo problemático, é portador de ideais e pode ser representante da problemática de seu tempo. Oskar nasce plenamente desenvolvido em termos intelectuais, é essencialmente irônico diante da matéria narrada, não busca um aprimoramento de conduta, como ocorre ao herói romanesco, que tem nessa busca intenção fundamental e determinante para a forma do romance. O único objetivo parece ser cumprir o plano estabelecido no início da narrativa, o registro de suas memórias.

É preciso salientar que, quando Oskar deixa claro o plano da narrativa, afirma tratar-se de uma ação sigilosa, pois nunca poderia ter solicitado suprimentos para tal projeto a uma de suas visitas, por classificar o papel como algo perigoso. Os questionamentos a respeito da matéria a ser narrada aumentam diante de tal caracterização. Entende-se que todo esse cuidado se refere à matéria histórica, um período de intensas transformações sociais e políticas, como a Primeira e Segunda Guerra Mundial, que no ano de publicação (1959) ainda eram questões delicadas. Não era tarefa simples tratar de assuntos como os apresentados em $O$ tambor, principalmente da forma como foram estruturados e desenvolvidos. Trata-se de um mundo de "crime e castigo" narrado pelo interno que sobreviveu à catástrofe.

Após a digressão sobre o romance moderno, Oskar inicia o que será sua narrativa, momento em que acontece a primeira inscrição de si mesmo em terceira pessoa. É como se, aqui, o narrador em primeira pessoa tomasse a posição de autor de suas memórias, vendo a si mesmo na condição de personagem, como as demais que serão inseridas na narração.

\footnotetext{
6 “Als ich zu Bruno sagte: Ach Bruno, würdest du mir fünfhundert Blatt unschuldiges Papier kaufen? Antwortete Bruno, zur Zimmerdecke blickend und seinen Zeigefinger, einen Vergleich herausfordernd, in die gleiche Richtung schickend: Sie meinen weißes Papier, Herr Oskar”'(p.10)
} 


\section{Pedro, E. S. - Os dois Oskar Matzerath}

A todos vocês que, fora do hospício, levam vidas agitadas, a vocês, amigos e visitantes semanais que não suspeitam de meu estoque de papel, apresento a avó materna de Oskar (p. 14). ${ }^{7}$

A alternância das pessoas no discurso é um mecanismo que surpreende e em alguns momentos pode causar uma confusão para o leitor ao longo do desenvolvimento da narrativa. É como se o "eu" de Oskar interno do hospício se projetasse em um "ele" em momentos do passado. Essa alternância intensifica-se após o nascimento de Oskar, quando ele passa a fazer parte do universo criado pelo relato de suas memórias como personagem. Dessa forma, o universo ficcional do narrador terá duas visões: a do Oskar interno do hospício e a visão de Oskar narrada por esse interno sob a perspectiva da criança de três anos de idade.

Oskar nasce nos primeiros dias setembro de 1924, dotado de consciência a respeito das misérias que cercam a sociedade e com capacidade de escolha sobre seu destino desde o momento de seu nascimento, quando sua mãe promete a ele um tambor de presente quando completasse três anos. Ele decide, então, em seu aniversário de três anos, diante do universo que se configura à sua volta, não mais crescer, não compartilhando da posição dos adultos e de sua perspectiva, permanecendo com a estatura de uma criança de três anos. Tais características lhe deram, como observa Marcus MAZZARI (1999), uma perspectiva rasteira, que facilita sua movimentação por diversos ambientes e situações. A mobilidade de Oskar não se encerra no fato de ter aparência de três anos, mas também no modo como o narrador articula a narrativa tendo como local de enunciação o hospício.

Ao longo da narrativa são apresentados outros dons fantásticos de Oskar Matzerath, como sua voz "vitricida" e sua habilidade em tocar o inseparável instrumento. Dons que podem ser interpretados como canais de comunicação de Oskar com o universo dos adultos, até como forma de influência emocional, de manipulação, o que se constata em várias passagens do romance, a exemplo do comício no campo de maio no capítulo "A tribuna" (Die Tribüne), na utilização da voz como instrumento de entretenimento, quando Oskar faz parte da companhia de teatro do front (Bebras Fronttheater) e no terceiro livro, quando utiliza seu tambor para fins mercadológicos ainda sob influência de seu mestre Bebra.

\footnotetext{
7 "Ihnen allen, die Sie außerhalb meiner Heil- und Pflegeanstalt ein verworrenes Leben führen müssen, Euch Freunden und allwöchentlichen Besuchern, die ihr von meinem Papiervorrat nichts ahnt, stelle ich Oskars Großmutter mütterlicherseits vor." (p. 11)
} 


\section{Pedro, E. S. - Os dois Oskar Matzerath}

É possível afirmar que há, então, dois níveis de narrativa: um do interno do hospício, autor das memórias no presente da enunciação, outro do universo criado a partir das memórias, com referências ao passado, tendo o tambor como elemento configurador. É por meio dele que se tornará possível, segundo Oskar, narrar suas memórias.

Contudo, no decorrer da narrativa é perceptível que a alternância entre a primeira e a terceira pessoa não obedece a um mecanismo rígido. Poderia ser proposto, por exemplo, que o o narrador em primeira pessoa seria utilizado quando se tem a narrativa no presente da enunciação, Oskar no hospício, enquanto, no momento em que se tratasse das narrativas de sua memória, o narrador estaria se referindo a Oskar na terceira pessoa. Este mecanismo não é aplicável. Há uma alternância de tempo e de pessoa que pode confundir o leitor em alguns momentos, estratégia que poderia ser chamada de "jogo", estabelecido por Oskar e, na medida do possível, deve ser acompanhado por essa variação.

Considerando o exposto, está-se diante de um narrador em primeira pessoa que registra sua experiência dentro do universo ficcional. Mas a situação é alterada no momento em que Oskar inicia a narração, distanciando-se do universo a ser narrado. Uma proposição possível seria a de que, nesse momento, Oskar se tornaria mediador entre o que seria seu universo do presente da narrativa - a clínica - e seu universo ficcional - as memórias, o que lhe dá mobilidade e perspectiva distanciada, Oskar se tornaria personagem de sua narrativa em sua autobiografia ficcional e gerando, a partir de sua própria terceira pessoa, variações entre uma limitação real de ponto de vista e uma onisciência virtual. Contudo, apesar do controle sobre a narrativa, Oskar não se apresenta como um narrador onisciente, por exemplo, um narrador que tem a liberdade de narrar de diversos ângulos, ultrapassando limites de tempo e espaço, mas sim pode-se denominar que Oskar apresenta uma onisciência de hospício, isto é, dependente do espaço no qual o narrador enuncia. Por meio desta, os pensamentos de suas personagens não são apresentados; pelo contrário, o narrador faz questão de deixar claro em alguns momentos que não tem o poder de entrar na consciência das personagens inseridas em seu registro. Em contraposição a esse dado, notamos seu interesse pela superfície desses caracteres, os quais Oskar manipula, não sem evitar tensões decorrentes dos momentos em que há o choque entre as personagens das memórias, descritas “objetivamente", e a "realidade" presente. Seu poder está no controle do que ocorre externamente às outras personagens, à configuração de seu universo ficcional. 


\section{Pedro, E. S. - Os dois Oskar Matzerath}

É preciso também levar em consideração que reconstruir o passado significa aproximar-se de acontecimentos sistematicamente, entrando em contato com aqueles que não fazem parte da sua identidade atual. Isso justificaria a utilização dos dois tipos de pronome, marcando que o Oskar do presente narrativo não é mais o Oskar criança; assim, para a reconstrução desse passado, mesmo que não de forma sistematizada, é preciso criar um outro eu, marcando o distanciamento e produzindo, em contrapartida, instabilidade. A personagem Oskar - a personagem das memórias - é a objetivação do eu do hospício; aqui há o distanciamento. Por outro lado, essa marca surge do eu Oskar, o interno que narra, o que acaba diminuindo a distância e aproximando a matéria narrada do hospício. Tem-se, assim, não apenas um movimento protocolar de permuta entre o eu e ele, mas o movimento complexo e instável da construção e objetivação das memórias.

O início da narrativa, até o momento em que Oskar julga que "ninguém deve descrever sua vida sem ter a paciência de antes datar a própria existência, recordar ao menos a metade da vida de seus avós" 8 (p. 14), indica que o narrador se encontra em um presente narrativo que o leitor saberá, no decorrer da leitura, estar situado temporalmente entre 1952 e 1954. Essa configuração coloca o narrador em uma posição privilegiada diante dos acontecimentos narrados, já cristalizados, em uma perspectiva distanciada tanto do ponto de vista temporal quanto do ponto de vista espacial, pois o ambiente da clínica acaba se tornando um refúgio onde ele pode se proteger do que o cerca, como ele mesmo indica nos primeiros parágrafos da narrativa.

É preciso salientar que o período da narrativa de Oskar é aquele da elaboração do processo judicial instaurado contra ele, do qual o leitor somente toma conhecimento ao fim da leitura. Esse processo pode ser entendido em duas acepções: o processo judicial, a respeito do crime supostamente cometido por Oskar, e o processo da construção das memórias, que dará substrato à matéria histórica ali avaliada.

Dentro daquilo que o narrador denomina como memória estão também fatos que ele não presenciou - aqueles compreendidos entre 1899 e 1924, ano do nascimento de Oskar. Utilizando para a narração desses episódios o mecanismo do flashback, os fatos narrados nesse intervalo possivelmente são criados por meio de memórias suscitadas pelo álbum de

\footnotetext{
8 “[...] denn niemand sollte sein Leben beschreiben, der nicht die Geduld aufbringt, vor dem Datieren der eigenen Existenz wenistens der Hälfte seiner Großeltern zu gedenken.” (p.11)
} 


\section{Pedro, E. S. - Os dois Oskar Matzerath}

família, um dos elementos inseparáveis e importantes para a configuração do universo ficcional de Oskar, pois "que romance - ou qualquer outra coisa no mundo - poderia ter a dimensão épica de um álbum de fotografias"9 (p. 55)?

A partir do conhecimento do plano desse narrador, bem como de sua perspectiva, seria possível afirmar que a narrativa poderia ser chamada de "narrativa dentro da narrativa". Entre os dois planos narrativos - o do presente, na clínica psiquiátrica, e o do passado, das memórias -, o primeiro é o que se poderia chamar de moldura da narrativa, mas sem ser uma moldura fixa. Trata-se de uma estrutura dinâmica, que se infiltra na narrativa do passado sem ter a rigidez desse procedimento, de forma que, além dessa dinâmica dos planos de narrativa, o narrador que apresenta os acontecimentos em ordem cronológica antecipa, em algumas passagens, acontecimentos posteriores. Percebe-se que em determinados momentos, o presente da narrativa das memórias se mistura com os diversos passados do narrador, intercalando acontecimentos dentro da linha cronológica que ele propõe. São planos de passado e presente em interseção constante ao longo da narrativa.

Para demonstrar como chegou à perspectiva narrativa apresentada até o momento, Grass, em seu texto "Rückblick auf Die Blechtrommel oder der Autor als Fragwürdiger Zeuge" ["Retrospectiva sobre $O$ tambor ou o autor como testemunha duvidosa"], afirma que essa perspectiva somente foi concebida na terceira versão para o romance e que, a partir da elaboração da primeira frase, foi possível estruturar a narrativa como ela hoje se apresenta.

Com a primeira frase: "Admito: sou interno de um hospício", caiu a barreira, fluiu a linguagem, força da memória e fantasia, prazer lúdico e obsessão pelo detalhe. Partiram as rédeas largas, resultando capítulos atrás de capítulos, eu saltava, onde havia buracos que impediam o fluxo da narrativa, vieram até mim histórias de teor local, caixinhas se abriam e liberaram odores, criei uma família que crescia sem controle, entrei em atrito com Oskar Matzerath e os seus por causa dos bondes e seu trajeto, eventos simultâneos e a pressão absurda da cronologia, por conta do direito de Oskar em relatar em primeira ou terceira pessoa, por causa de sua culpabilidade verdadeira e de sua culpa fingida (GRASS 1979:18, tradução nossa.). ${ }^{10}$

\footnotetext{
9 “[...] welcher Roman hätte die epische Breite eines Fotoalbums?” (p. 37)

10 "Mit dem ersten Satz: "Zugegeben: ich bin Insasse einer Heil- und Pflegeanstalt..." fiel die Sperre, drängte Sprache, liefen Erinnerungsvermögen und Fantasie, spielerische Lust und Detailobzession an langer Leine, ergab sich Kapitel aus Kapitel, hüpfte ich, wo Löcher den Flu $\beta$ der Erzählung hemmten, kam mir Geschichte mit lokalen Angeboten entgegen, sprangen Döschen und gaben Gerüche frei, legte ich mir eine wildwuchernde Familie zu, stritt ich mit Oskar Matzerath und seinem Anhang um Straßenbahnen und deren Linienführung, um gleichzeitige Vorgänge und den absurden Zwang der Chronologie, um Oskars Berechtigung, in erster oder dritter Person zu berichten, um seine wirklichen Verschuldulgen und um seine fingierte Schuld." (GRASS 1979:18).
} 
Pedro, E. S. - Os dois Oskar Matzerath

O autor afirma que, inicialmente, a personagem, que não se chamava Oskar, pertencia a um poema, morava no alto de uma torre em uma cidade, a partir da qual poderia observar todos os acontecimentos de forma distanciada, sem contato direto com a sociedade. O poema e essa perspectiva foram abandonados, restando da concepção do poema apenas o distanciamento da personagem. Além do distanciamento, o autor procurava outra característica: a mobilidade.

Diante dessa configuração de estrutura narrativa, na qual é oferecido um foco em que o narrador apresenta relatos em primeira e terceira pessoa, há, ao mesmo tempo, a distorção e a deformidade que lhe permitem narrar a duplicidade que ele encarna; assim, o modo com que se presta a participar das ações passadas em oposição a seu lugar bem definido e seguro faz com que se escamoteie a própria deformidade de contar. A deformidade é o princípio ativo da narrativa, que para o leitor se apresenta materialmente na deformidade física de Oskar, o interno do hospício, em contraste com a imagem de Oskar com aspecto físico de uma criança de três anos. A deformidade de Oskar se faz presente de maneira enfática principalmente no terceiro livro do romance.

No que se refere ao recorte aqui apresentado, o narrador não se apresenta somente em primeira pessoa, mas também se objetiva em um Ele para contar sua história, num jogo entre passado e presente, entre o Eu e o Ele, iluminando a todos os outros personagens, aos quais empresta sua deformidade.

\section{3- $\bigcirc$ filme}

Ao se deparar com a narrativa literária ou cinematográfica, o leitor e o espectador leva consigo a experiência de mundo na interpretação de uma obra, criando expectativas, hipóteses, realizando atividades para construir uma narrativa coesa Pode utilizar esquemas narrativos que definem os acontecimentos e os unificam por meio de princípios da causalidade, tomando como objetivo principal tornar a história apresentada inteligível. No caso dos objetos centrais dessa análise, levando em consideração que o filme ao qual o espectador assiste é baseado em uma obra literária, as expectativas interpretativas e as experiências de leitura adquiridas potencializam-se. 


\section{Pedro, E. S. - Os dois Oskar Matzerath}

Ao assistir uma adaptação cinematográfica de um romance, o espectador está diante de uma leitura particular da obra. E sabe-se que um romance, mesmo provocando inúmeras interpretações, desenvolve dentro de seu próprio corpo um processo de seleção. Pode-se afirmar, então, que a interpretação do romance pelo diretor do filme, no caso, será particular. Ela não pode ser entendida como um mero ato de decodificação, mas como um espaço de construção de sentido no qual as escolhas exprimem uma organização de significantes, designam instruções para produção de um significado. É isso que o diretor procura fazer em sua adaptação, ao estabelecer limites para sua interpretação e espera que o espectador possa também construir sua narrativa baseada no filme produzido.

Diante do que foi apresentado a respeito do romance, para a transposição para o cinema, seriam necessárias algumas alterações na estrutura da narrativa na qual foi baseada. Aqui tem início o processo que envolve uma série de fatores internos e externos à obra. Internos no que toca o recorte que delimita a extensão do filme, o tipo de narrador adotado, as adaptações realizadas em relação à constelação de personagens, o recorte histórico e a adaptação da matéria que compõe o romance. Externos no que se refere à dificuldade de execução do roteiro, às conversas entre diretor e roteiristas, à decisão sobre o idioma a ser falado no filme - diretamente relacionado a questões financeiras, pois implicaria até a escolha dos atores para interpretações dos papéis - às locações e ao contexto histórico do presente da filmagem, entre outros.

Assim, a primeira preocupação de Schlöndorff foi quanto ao tipo de narrador que seria utilizado para a organização da matéria a ser narrada. Diante da complexidade apresentada pelo narrador do romance, o diretor necessitou realizar um recorte na narrativa, atento ao fato de ter de manter a coerência narrativa, mesmo que isso custasse a alteração de uma das principais, se não a principal, característica da obra: o narrador.

Schlöndorff procurou trabalhar a sintaxe do texto, os tipos de construção que Grass apresenta, e transportar todos esses aspectos para a ótica da câmera. Um longo processo de dois anos que abarca conversas com o autor, produtores e roteiristas, tentando transpor as interseções de níveis narrativos, sobreposições temporais que se tornaram um desafio para a equipe. Grass também trabalhou na produção do roteiro e edição do filme.

Assim como Grass necessitou de uma estrutura adequada para a matéria a ser narrada, para transpor a complexa estrutura narrativa do romance na tela o cineasta também necessitou buscar a perspectiva narrativa adequada. No caso de Schlöndorff, não estava em jogo apenas a 


\section{Pedro, E. S. - Os dois Oskar Matzerath}

transposição pura e simples da obra, mas também o fato de que em 1979 vinham à tona materiais históricos novamente em debate que seu filme ajudaria a fomentar, além da perspectiva distanciada para tratar dos acontecimentos históricos da primeira metade do século XX e de uma nova divulgação da obra, reavivando questões presentes em seu conteúdo.

Pensando na viabilidade de transposição do texto e suas consequências, a posição do interno do hospício teve de ser descartada, até porque, caso a opção eleita fosse manter a mesma estrutura do romance, a narrativa do filme teria de ser prolongada pelos três livros. Optando por não adotar a mesma perspectiva, Schlöndorff faz um recorte temporal, apresentando a narrativa de Oskar de 1889 a 1945, o que corresponde aos dois primeiros livros do romance, período que compreende fatos históricos importantes para a Alemanha e para a cidade de Danzig e de repercussão mundial.

A necessidade da fidelidade à qual os críticos de cinema da época se referem tem como primeiro elemento a cena inicial do filme, que instaura as comparações entre o filme e o romance. $\mathrm{O}$ filme tem início com uma tomada de um campo aberto, mais especificamente um campo de batatas, plano no qual se vê ao longe uma mulher. Em seguida, o espectador é surpreendido com uma voz off : "Ich beginne weit vor mir" (Vou começar bem antes de mim.) (GRASS \& SCHLÖNDORFF 1979:18). ${ }^{11}$

Com a escolha desse mecanismo, a narração em voz off, o diretor transforma a narrativa cinematográfica em um longo flashback, em um presente narrativo não datado dessa voz, que o espectador identifica como de uma criança, diferentemente do que ocorre no romance, sem uma localização espacial ou temporal do narrador. Pode-se afirmar isso tendo como base o fato de que a primeira referência visual desse narrador, ao qual atribuímos a voz off, é a criança Oskar Matzerath.

\footnotetext{
11 Todas as referências aos diálogos do filme são extraídas de DIE BLECHTROMMEL. Direção: Volker Schlöndorff. Produção: Anatole Daumane Franz Seitz.Intérpretes: Mario Adorf, Angela Winkler, David Bennent, Daniel Olbrychski, Katharina Thalbach, Charles Aznavour, Tina Engel, Berta Drews, Fritz Hakl, Mariella Oliveri e outros. Roteiro: Volker Schlöndorff, Franz Seitz e Jean-Claude Carrière. Música: Maurice Jarre. Alemanha / França / Polônia / Iugoslávia: Bioskop Film, 1978. 1 DVD (136 min.), son., leg., color. Também tendo como base o roteiro do fime: GRASS; SCHLÖNDORFF, Volker. Die Blechtrommel als Film. Frankfurt a. M.: Zweitausendeins, 1979.
} 


\section{Pedro, E. S. - Os dois Oskar Matzerath}

Diante desse narrador que não se apresenta localizado temporal ou espacialmente, como ocorre no romance, não há uma interseção entre tempos e espaços tão presentes como há na narração do interno do hospício. Há o presente narrativo, ainda que indeterminado, o que favorece a estratégia da narrativa, e o passado da narrativa, distanciado dos acontecimentos. A voz off é uma informação fora da sequência de imagens que se vê na tela, motivada psicologicamente em relação a uma personagem, no caso específico desse filme. A natureza dessa voz configura a construção da narrativa pelo espectador, pois é por ela que ele será guiado.

Toda a tensão propiciada pelo ambiente do hospício se perde na transposição desse narrador. A contextualização histórica que o ponto de partida da narração de Oskar oferece em 1954 também se perde. O que é apresentado, em um primeiro momento, é o olhar de um narrador que pretende narrar sua história, mas sem um plano para tal, sem um objetivo aparente. Ele não suscita no espectador as dúvidas, a perseguição de uma explicação do porquê de tal perspectiva narrativa. Nesse caso, a voz off se tornou apenas a condutora da narrativa.

A narrativa do filme também apresenta dois níveis, como se pode perceber a partir desse início: o passado narrado desfila com o suceder das cenas que compõem o trajeto do protagonista, e o presente do narrador, que se dirige diretamente ao espectador por meio da voz off.

Também será por meio desse olhar que o espectador terá contato com o modo com que os acontecimentos históricos são vistos por essa personagem. O grande diferencial é que o romance deixa no leitor a impressão de que ele acompanha o processo de escritura das memórias de uma personagem que, mesmo diante de toda a dúvida que ela suscita por conta de sua condição, se utiliza de instrumentos para o procedimento de seu plano: o tambor, o álbum de família, a interlocução com o enfermeiro e os materiais utilizados para o registro da memória. O leitor, ao final, entende que o processo da reconstrução do registro das memórias corresponde ao período do processo judicial ao qual Oskar foi submetido. No filme há apenas a voz que conduzirá o espectador por sua narrativa, sem mostrar um plano ou um motivo aparente para tal.

Assim, é apresentada no início do filme Anna Bronski, a avó de Oskar, que está sentada no campo de batatas após um dia de trabalho quando vê ao longe um pequeno homem, Joseph Koljaiczek, sendo perseguido por dois soldados e que, ao aproximar-se dela, 


\section{Pedro, E. S. - Os dois Oskar Matzerath}

pede abrigo embaixo de suas saias. Diante de tal súplica, Anna concede abrigo, salvando-o. O homem, futuro avô de Oskar, aproveita-se da situação e a engravida.

Tanto no romance quanto no filme, essa cena pertence a um período (1899 a 1924) que o narrador não presencia, mas constrói, possivelmente, a partir de outros registros - no caso do romance, o inseparável álbum de fotografias ou, quem sabe, o relato de outras pessoas, como sua mãe ou avó. No caso do filme, o diretor utilizou recursos de tratamento de película e velocidade para marcar a diferença entre aquilo que é narrado a partir da experiência de Oskar e o que não foi vivenciado por ele. Nessa primeira sequência, em que Oskar apresenta a origem e constituição de sua família desde o encontro de sua avó com Joseph até o dia de seu nascimento, é possível perceber as diferenças em relação ao tempo que Oskar vivenciou.

Assim como no romance, não se sabe inicialmente quem está contando a história. E, como também ocorre no livro, o espectador é apresentado formalmente ao narrador quando este se refere a si mesmo, ainda no momento em que não faz parte da narrativa como personagem, quando apresenta ao espectador o tipo de relacionamento que sua mãe, Agnes, estabelece com seus pretendentes, Jan e Alfred, triângulo amoroso que aparecerá constantemente ao longo do filme. Especificamente na sequência Markt am Hafen (Mercado no porto $)^{12}$, Agnes decide quem será seu futuro marido, tendo que escolher entre o polonês naturalizado Jan e o alemão Alfred, no momento histórico em que Danzig fora elevada a cidade livre. É uma sequência em que o espectador toma conhecimento de quem é o narrador do filme, o dono da voz off.

Oskar (voz off): Os dois tão diferentes, apesar dos sentimentos semelhantes por mamãe, gostavam um do outro e nessa trindade trouxeram a mim, Oskar, ao mundo (GRASS \& SCHLÖNDORFF 1979:29, tradução nossa). ${ }^{13}$

Agnes está de braços dados com seu escolhido, Alfred, e, em seguida, de mãos dadas com Jan, configurando o triângulo amoroso. Esse triângulo se tornará leitmotiv do filme. Para MAZZARI (1999), algumas personagens manifestam as tendências ideológicas da época retratada, pois, como foi apresentado, a história da cidade de Danzig e sua relação com a

\footnotetext{
12 Os títulos das cenas seguem a descrição do roteiro do filme publicado em: GRASS, Günter SCHLÖNDORFF, Volker. Die Blechtrommel als Film. Frankfurt a. M.: Zweitausendeins, 1979

13 „Oskars Stimme: Die beiden so verschiedenen, doch in Bezug auf Mama einmütigen Herren, fanden Gefallen an einander, und in dieser Dreieinigkeit haben sie mich, Oskar, in die Welt gesetzt." (GRASS \& SCHLÖNDORFF 1979:29).
} 


\section{Pedro, E. S. - Os dois Oskar Matzerath}

Alemanha e a Polônia têm papel importante no enredo. O autor considera que o triângulo amoroso entre Alfred Matzerath, Agnes e seu primo Jan Bronski "parece refletir em círculo privado, a correlação de forças entre o Reich alemão, a cidade-livre e a república polonesa" (MAZZARI 1999:129). Essas relações estarão muito marcadas ao longo do filme por meio de enquadramentos específicos entre os três que compõem o triângulo, jogos de espelhamento, além das alusões aos avanços da força do Reich alemão em relação à Polônia.

No romance, quando o narrador é identificado, está evidente o objetivo da construção da narrativa: o registro exato das memórias; no filme, por sua vez, quando a identificação ocorre, o que é evidente é a configuração familiar e a localização histórica de acontecimentos importantes para o período.

A complexidade do foco narrativo apresentada no romance, com a alternância entre a primeira e a terceira pessoa, será transposta para o filme com a utilização da voz off e da perspectiva de câmera adotada em certos momentos pelo diretor. Esses elementos serão o olhar desse narrador, determinando como serão caracterizados os personagens e a ambientação de sua narrativa. Esse olhar é uma das características mais marcantes da personagem Oskar Matzerath. Seus olhos azuis, considerados “impenetráveis”, serão responsáveis por conduzir a narrativa.

Esses olhos azuis de extrema beleza se destacam em meio à deformidade e destruição apresentadas no romance. Na narrativa, há a beleza em meio à destruição, que será ainda mais acentuada no terceiro livro, quando Oskar, em sua fase de modelo para os alunos da escola de Belas Artes, nunca consegue ser reproduzido em sua essência, conseguem reproduzir sua deformidade, mas não a beleza de seus olhos. Já no filme, os belos olhos estão presentes na caracterização de Oskar, mas sem que transcendam, sem que se misturem à destruição e à deformidade que não tem ligação com a figura da criança, presente apenas no romance. $\mathrm{Na}$ película, não há como referência Oskar deformado, o que é apresentado é justamente a criança.

No romance, os alunos acentuam a forma de sua corcunda adquirida, toda a sua deformidade, mas não seus olhos. O que se percebe da discussão, levantada pelo texto, é que o compromisso daqueles artistas era com a arte, não com o tempo, com a história ou com os acontecimentos que ainda assombravam a todos no pós-guerra. Oskar funciona como a alegoria daquele tempo. Oskar tentava mostrar a todos, enquanto posava de modelo, que o pós-guerra, a reforma monetária, os artistas, todos tinham responsabilidade diante dos 


\section{Pedro, E. S. - Os dois Oskar Matzerath}

acontecimentos. Os artistas procuravam retratar Oskar como se pudessem se distanciar da loucura, em quadros, gravuras, mas não conseguiam colocá-lo de pé em uma armação de escultura. Procuravam o distanciamento da catástrofe que há pouco vivenciaram. Nesse contexto, a deformação não cabe apenas ao interno do hospício, mas também a todos que o cercava.

A preocupação do diretor com a transição entre o narrador e a personagem de sua narrativa, que no romance ocorre entre a primeira e terceira pessoa, levou-o a dividir o que se pode denominar visão subjetiva de Oskar enquanto narrador: de um lado, a voz off, subjetiva; do outro, o ponto de vista objetivo de Oskar, o menino - num jogo próximo das variações entre primeira e terceira pessoas do romance. Assim, há dois comportamentos diferentes da câmera ao longo do filme. Quando o ponto de vista é o do narrador, tem-se o que seria no romance a posição de Oskar confinado no hospício. São os momentos em que há a incursão da voz off, os instantes da configuração dos espaços e da situação da cena. Em outras passagens, há a apresentação do ponto de vista do menino Oskar, personagem da narrativa.

As primeiras sequências em que é possível observar este câmbio são as denominadas "Wohnung Matzerath Schlafzimmer" [Casa dos Matzerath, quarto de dormir] e "Mutterleib der Agnes Matzerath” [Ventre de Agnes Matzerath]. No momento do nascimento de Oskar, o narrador apresenta o ambiente em que Agnes está dando à luz Oskar e, ao mesmo tempo, também mostra a condição do embrião dentro do útero. $\mathrm{O}$ momento do nascimento mostra o ponto de vista do bebê diante do universo que o cerca e o instaura como personagem da narrativa, tendo o universo observado por ele.

Outra sequência na qual é muito evidente o câmbio entre essas duas posições é a da comemoração de aniversário de três anos de Oskar, "Wohnung Matzerath Wohnzimmer" [Casa dos Matzerath, sala], data em que decide interromper o seu crescimento. Nessa cena, a constelação de personagens que configuram o universo pequeno-burguês no qual Oskar está inserido é apresentada sob duas perspectivas, a do narrador e da personagem. As relações que se estabelecem entre os convidados, como a infidelidade de sua mãe ao manter um relacionamento com quem Oskar chamava de "pai presuntivo", Jan Bronski, são apresentadas de modo a estabelecer dois níveis de percepção: (1) o superficial, o das aparências, no qual os narradores objetivo e subjetivo se apresentam ao mesmo tempo e (2) o nível das relações adúlteras em que também há esse câmbio. A essa altura, já se sabe que o menino tem os sentidos todos desenvolvidos e a capacidade de avaliação aguçada do universo ao redor. 


\section{Pedro, E. S. - Os dois Oskar Matzerath}

O nível superficial é o do jogo de skat, recorrente na narrativa, em que o triângulo amoroso é apresentado, mas não fica evidente aos olhos de todos, e, em outro nível, o relacionamento adúltero de Agnes e Jan é mostrado ao espectador sob a mesa por meio de um jogo de sedução presenciado por Oskar. Nesse ambiente familiar é que Oskar tem a dimensão do universo pequeno-burguês no qual está inserido.

O procedimento adotado por Schlöndorff nessa sequência deixa claro que o diretor quer manter a perspectiva da criança de três anos. A sequência é iniciada em um plano com a câmera na altura de 90 centímetros, um pouco acima da altura da mesa, como se a visão fosse a do narrador; ao mesmo tempo, percebe-se que a seu lado há a visão do menino Oskar, mostrando o mundo das aparências. É como se os dois presenciassem, ao mesmo tempo, a cena do jogo de cartas e a cena de adultério. Notamos que nessa sequência a voz off do narrador não conduz a cena. O que conduz o espectador é apenas o olhar do narrador por meio da câmera. O espectador tem a sensação de estar acompanhando tudo sem o filtro do narrador, mas está sendo conduzido por ele.

Nos diários de filmagem, Volker Schlöndorff esclarece qual é o seu objetivo com o ponto de vista empregado, afirmando que o que era filmado, a perspectiva, tentava ser fiel ao que Oskar veria se fosse ele quem dirigisse o filme: uma perspectiva absolutamente subjetiva de tudo o que era representado. ${ }^{14} \mathrm{O}$ espectador tem a impressão de ter a mesma visão de Oskar. Assim, por ser uma perspectiva subjetiva - o olhar de Oskar conduzindo o espectador - o diretor utilizou o recurso técnico com uma câmera com altura de 90 centímetros na maior parte da filmagem, para que o espectador tivesse a perspectiva do menino Oskar. O jogo entre a primeira e a terceira pessoa, mesmo que reproduzido no filme, não nos dá a dimensão do que é o narrador Oskar tal como se manifesta ao longo do romance. O que é apresentado é uma intervenção menor desse narrador e uma interação maior de Oskar com os outros personagens.

A presença constante do narrador no livro faz o espectador construir e agregar elementos a Oskar ao longo da narrativa, diferentemente do filme, no qual a imagem de Oskar é projetada e definida tanto pelo olhar da câmera como pela voz off do narrador. A pequena

\footnotetext{
${ }^{14}$ Was Oskar sieht, müssen wir filmen. Er ist unser Standpunkt, keine objektive Geschichtserzählung.“ (SCHLÖNDORFF 1979: 60)
} 


\section{Pedro, E. S. - Os dois Oskar Matzerath}

interferência da voz off faz com que, mesmo com as marcações de passagem do tempo que ficam evidentes ao longo do filme, entenda-se que Oskar se manteve o mesmo, sem grandes mudanças de características físicas ou mentais, sem que a ironia e o distanciamento, que parecem características importantes de Oskar no romance, fiquem evidentes no filme.

O diretor procura fazer com que todas as ações de Oskar tenham como causa aquilo que é apresentado a ele no universo que o rodeia de forma mais próxima, o universo familiar. Todas as suas reações terão como causa elementos desse ambiente - o adultério da mãe, as relações estabelecidas entre as outras pessoas que frequentam sua residência -, sem ligação direta com a situação social e histórica, que, enfim, serviria como mero pano de fundo para a narrativa.

Até o momento e ao longo do restante da narrativa fílmica, percebe-se que a intenção de Oskar ao manter-se com três anos de idade não é a mesma apresentada pelo romance. Neste há uma criança extraordinária que nasce com o olhar crítico a respeito do universo que a rodeia, mas que difere de uma criança "comum". Na interpretação de David Bennent não fica expresso nenhum grau da ironia ou perspicácia de que a personagem de Oskar necessita para viver suas peripécias. Mesmo em cenas em que notamos uma maior dedicação da direção de atores pelo diretor, como naquelas com a Companhia de Teatro do Front, nos diálogos com Bebra, com Roswitha e com Maria, não é possível identificar a dubiedade que Oskar suscita no romance. Em alguns momentos, o que ajuda a interpretar certas ações do menino são as variações da modulação da voz off do narrador.

As cenas nas quais Oskar precisa colocar em prática seus desejos enquanto criança, como em „Wohnung Matzerath, Wohnzimmer“ [casa dos Matzerath, sala], quando tentam retirar dele seu tambor destruído para substituir por um novo que não o machuque, há ali a expressão genuína do que Schlöndorff quer com seu filme. Segundo suas declarações, o diretor quer apresentar a história de um menino de três anos que se recusou a crescer sem torná-lo alegoria de uma época. Cenas que mostram esse objetivo do diretor são as que apresentam a vida de Oskar no ambiente do subúrbio de Langfuhr, a tentativa de aprender a ler e a escrever, a recusa de ir à escola, as traquinagens no consultório do médico ao quebrar todos os vidros com sua voz vitricida ou sendo perseguido pelas crianças do bairro que o obrigam a tomar uma sopa com ingredientes nada apetitosos.

A carga de negatividade atribuída a Oskar no romance por sua posição de interno do hospício, além de sua deformidade, que o leitor só compreenderá melhor no terceiro livro, é 


\section{Pedro, E. S. - Os dois Oskar Matzerath}

retirada desse menino apresentado no filme e do narrador. O que sobra ao espectador é a experiência do tocador de tambor com sua música e sua voz em trânsito pela sociedade da época.

Schlöndorff procura salientar em suas entrevistas, como a concedida a Bion Steinborn para a revista Filmfaust (1979), que não procurou fazer da história de Oskar uma parábola, nem da criança um símbolo; procurou, sim, criar uma biografia real de um menino que decide não mais crescer. Segundo o diretor, não queria transformar Oskar em um anão alegórico,

Diante do que foi afirmado até o momento, levando em conta principalmente o que o diretor do filme apresenta, é possível entender a análise apresentada por NEUHAUS (1992) a respeito do filme. Em seu estudo sobre o romance, dedica pequena parte à adaptação cinematográfica e afirma, não apenas baseado no início de sua narrativa, mas também na caracterização das personagens e configuração da narrativa, que há ali uma "franqueza otimista" que contrasta com a organicidade pessimista do romance, dada já no início com a confissão do interno - pois pode-se questionar como alguém que tem como lugar de enunciação um hospício pode relatar uma experiência otimista. Esse choque, que é apresentado desde o início no que se refere à comparação entre as duas obras, terá reflexo, sobretudo, na configuração da personagem Oskar Matzerath, na constelação de personagens e, consequentemente, na organização do conteúdo apresentado nas duas obras.

O espectador, ao ser apresentado pela primeira vez à imagem dessa personagem, assusta-se, pois esperava que lhe fosse apresentado um bebê recém-nascido. Mesmo com as tentativas de aproximar o ator David Bennent, que na época tinha 12 anos, a um bebê, a imagem, que pode-se denominar como grotesca, de uma criança maquiada simulando um recém-nascido causa má impressão ao espectador. Nos diários de filmagem não fica clara qual a intenção de Schlöndorff ao utilizar o menino-ator David desde o nascimento de Oskar e não optar por um bebê. Interpreta-se essa escolha como forma de justificar, por meio da imagem de uma criança formada, o fato de o narrador Oskar explicar, então, o instante de seu nascimento, os sentidos já formados, a capacidade de perceber o universo à sua volta e, principalmente, a decisão de parar de crescer aos três anos.

Talvez a intenção de Schlöndorff seja realmente chocar o espectador desde a primeira veiculação da imagem de Oskar. Antes da saída do ventre de sua mãe, passando pelo colo da parteira até chegar à banheira, o espectador tem a impressão de que se trata de um bebê. Quando o foco muda para o narrador, contudo, e o espectador tem a visão de uma criança 


\section{Pedro, E. S. - Os dois Oskar Matzerath}

enorme que não cabe dentro da banheira, com feições de uma criança desenvolvida, há o primeiro choque. Nessa cena, Oskar, o recém-nascido, tem uma visão de como seria aos três anos, munido do tambor que sua mãe prometera. A imagem que Oskar projeta é a que será oferecida na cena do seu aniversário de três anos.

Em seguida, o espectador é apresentado ao Oskar projetado no pensamento do recémnascido, em seu aspecto de criança de três anos, em sua festa de aniversário, quando coloca em prática seu plano de interromper o crescimento. Nesse momento, é apresentado o ator David Bennent caracterizado como o menino Oskar.

Essa interpretação de Oskar apenas como criança potencializa o choque do espectador por conta da materialização da personagem na criança David Bennent, e esse choque é ainda maior em cenas que mostram a iniciação amorosa e sexual de Oskar. Sequências como as que mostram as relações com a madrasta Maria, por quem Oskar se apaixona, ou seu relacionamento dúbio com Lina Greff. O ritual do pó efervescente, a cena na cabine de troca de roupas, a cena em que encontra seu pai mantendo relação sexual com Maria. Pode-se levar em consideração esse aspecto por tratar-se de um ator que é uma criança e, muitas vezes, o espectador esquece que se trata de Oskar Matzerath, que é um personagem que não se coloca em evidência para o leitor, sempre em suspenso. O espectador leva em consideração apenas que quem está em cena é uma criança, praticando atos que não são compatíveis com os atos de uma criança, o que desloca o sentido da narrativa. O que choca o espectador não é o fato de ser Oskar Matzerath em cena, mas sim uma criança. Pode-se afirmar que não é possível que o espectador mantenha um distanciamento adequado da personagem para poder encará-la como um adulto. A dubiedade que está presente no menino Oskar do romance, que dá a ele a postura irônica, não está presente na atuação de David Bennent.

Percebe-se, ao final do filme, que o intuito de Schlöndorff de construir uma narrativa independente foi cumprido, pois seu principal elemento, Oskar Matzerath, apresenta uma caracterização diferente da que está presente no romance. A atuação do narrador em voz off e da personagem Oskar deveria conduzir o espectador à complexidade e à ironia que essa personagem suscita e que está presente no romance, para que houvesse uma reflexão mais aprofundada acerca dos acontecimentos históricos nos quais a personagem está inserida. 


\section{4 - Considerações Finais}

A estrutura narrativa do romance, amparada pela história e pela memória, com o constante câmbio de perspectiva de um narrador interno de um hospício, mantém-se coerente e firme, mesmo com todos os elementos que nos fazem por vezes questionar o registro de suas memórias, como os dons fantásticos de Oskar e suas peripécias

Na realização cinematográfica de Schlöndorff, encontramos outro Oskar, que não atormenta por sua deformidade física ou sua dubiedade, o que no texto de Grass é um modo de distanciamento do leitor em relação à personagem. O que está presente no filme é um menino traquinas de olhar aguçado que, diante de uma sociedade em transformação, não deseja crescer. Percebe-se a preocupação do diretor e dos roteiristas em manter a coerência narrativa tendo como base o romance, com a concentração da ação sempre relacionada aos movimentos históricos e movimentos familiares inconstantes, sua construção e dissolução, quase sempre relacionados a fins trágicos, ligados diretamente aos acontecimentos históricos.

A obra de Günter Grass vem passando por inúmeros questionamentos desde a publicação de suas memórias. O que deve ser ressaltado desse novo questionamento a respeito da obra de Grass é o poder que ela tem em retratar um período conturbado, promovendo reflexões e debates até hoje, tendo como principal foco o processo histórico e social. Trata-se de uma história que está sendo constantemente escrita e reescrita, de uma obra que apresenta, por meio de suas personagens, um quadro variado da sociedade contemporânea, que tem como principal representante a personagem Oskar Matzerath, e que propicia ao leitor a possibilidade de uma reflexão sobre o processo social. Reflexão que em alguns momentos pode incomodar e fazer com que seja escutada, em meio a ela, a canção que tanto incomodava a Oskar: "A Bruxa Negra está aí? Sim, sim, sim ${ }^{15}$ !”.

\section{Referências bibliográficas}

BARUDIO, Günter. "Günter Grass: Im Filmbild bleibt das Literarische auf der Strecke.” In: Filmfaust 14. Berlim, Jun./Jul,1979, 19-27

15 “Ist die Schwarze Köchin da? Ja - Ja - Ja!” (p.493) 


\section{Pedro, E. S. - Os dois Oskar Matzerath}

BothEYROID, Paul F. Ich und Er. First and third person self-reference and problems of identity in three contemporary german-language novels. Paris: Mouton, 1976.

FRIEDMAN, Norman. Point of view in fiction, the development of a critical concept. In: STEVICK. Philip. The theory of the novel: a comprehensive anthology. New York: The Free Press, 1967

GaLle, Helmut Paul Erich . "Juventude no estado totalitário: as autobiografias de J. Fest, G. Grass, L. Harig, G. de Bruyn e Chr. Wolf". In UMBACH, Rosani Ketzer (Org.) Memórias da repressão. Santa Maria: PPGL - UFSM, 2008.

GERSTENBERG, Renate. Zur Erzähltechnik von Günter Grass. Heidelberg: Carl Winter Universitätsverlag, 1980.

GRASS, Günter. Die Blechtrommel Frankfurt a. M: Fischer Bücherei,1960.

; SCHLÖNDORFF, Volker. Die Blechtrommel als Film. Frankfurt a. M.: Zweitausendeins, 1979.

. "Rückblick auf Die Blechtrommel oder der Autor als fragwürdiger Zeuge". In: SCHLÖNDORFF, Volker. "Die Blechtrommel" Tagebuch einer Verfilmung. Darmstadt/Neuwied: Luchterhand, 1979. . O tambor. Tradução de Lúcio Alves. Rio de Janeiro: Nova Fronteira, 1982.

MAYER, Hans. Die umerzogene Literatur : deutsche Schriftsteller und Bücher 1945-1967. Berlin : Siedler, 1988.

MAZZARI, Marcus Vinícius. Romance de formação em perspectiva histórica: o Tambor de Lata de Günter Grass. Cotia: Ateliê Editorial, 1999.

NeuHaus, Volker. Günter Grass, Die Blechtrommel : interpretation. München : Oldenbourg, 1992.

SCHLÖNDORFF, Volker. "Die Blechtrommel" Tagebuch einer Verfilmung. Darmstadt/Neuwied: Luchterhand, 1979.

STANZEL, Franz K. Theorie des Erzählens. Göttingen : Vandenhoeck \& Ruprecht, 1985.

VORMWEG, Heinrich. Günter Grass. Hamburg: Rowohlt, 2002.

\section{Filme}

DIE BLECHTROMMEL. Direção: Volker Schlöndorff. Produção: Anatole Daumane e Franz Seitz.Intérpretes: Mario Adorf, Angela Winkler, David Bennent, Daniel Olbrychski, Katharina Thalbach, Charles Aznavour, Tina Engel, Berta Drews, Fritz Hakl, Mariella Oliveri e outros. Roteiro: Volker Schlöndorff, Franz Seitz e Jean-Claude Carriere. Música: Maurice Jarre. Alemanha / França / Polônia / Iugoslávia: Bioskop Film, 1978. 1 DVD (136 min.), son., leg., color. 